University of Nebraska - Lincoln

DigitalCommons@University of Nebraska - Lincoln

$10-1-2006$

\title{
High-energy product exchange-spring FePt/Fe cluster nanocomposite permanent magnets
}

\author{
X. Rui \\ University of Nebraska - Lincoln \\ Jeffrey E. Shield \\ University of Nebraska - Lincoln, jshield@unl.edu \\ Zhiguang Sun \\ University of Nebraska - Lincoln, zsun3@unl.edu \\ Lanping Yue \\ University of Nebraska-Lincoln, lyue2@unl.edu \\ Yinfan $\mathrm{Xu}$ \\ University of Nebraska - Lincoln, yxu2@unl.edu \\ See next page for additional authors
}

Follow this and additional works at: https://digitalcommons.unl.edu/physicssellmyer

Part of the Physics Commons

Rui, X.; Shield, Jeffrey E.; Sun, Zhiguang; Yue, Lanping; Xu, Yinfan; Sellmyer, David J.; Liu, Z.; and Miller, D.J., "High-energy product exchange-spring FePt/Fe cluster nanocomposite permanent magnets" (2006). David Sellmyer Publications. 95.

https://digitalcommons.unl.edu/physicssellmyer/95

This Article is brought to you for free and open access by the Research Papers in Physics and Astronomy at DigitalCommons@University of Nebraska - Lincoln. It has been accepted for inclusion in David Sellmyer Publications by an authorized administrator of DigitalCommons@University of Nebraska - Lincoln. 
Authors

X. Rui, Jeffrey E. Shield, Zhiguang Sun, Lanping Yue, Yinfan Xu, David J. Sellmyer, Z. Liu, and D.J. Miller 


\title{
High-energy product exchange-spring FePt/Fe cluster nanocomposite permanent magnets
}

\author{
X. Rui (corresponding author) and J.E. Shield, Department of Mechanical Engineering and Center for Materials \\ Research and Analysis, University of Nebraska-Lincoln
}

Z. Sun, L. Yue, Y. Xu, and D.J. Sellmyer, Department of Physics and Astronomy, Center for Materials Research and Analysis, University of Nebraska-Lincoln

\section{Z. Liu and D.J. Miller, Argonne National Laboratory, Argonne, IL}

Submitted August 2005; revised November 2005; available online December 2005; in print October 2006.

\begin{abstract}
In this paper, we report on the production of $\mathrm{Fe}$ cluster/FePt matrix nanocomposite permanent magnets. Monodispersed Fe clusters with sizes below $10 \mathrm{~nm}$ were formed by gas aggregation techniques. These Fe clusters were imbedded in an FePt matrix by alternate deposition from two sources. Specimens with a range of Fe cluster phase content from 0 to $30 \mathrm{vol} \%$ were produced by controlling deposition times from each source. As-deposited FePt formed in the A1 structure; thus, post-deposition heat treatment was necessary to form the hard magnetic $\mathrm{L}_{0} \mathrm{FePt}$ compound. A single-step heat treatment at $600{ }^{\circ} \mathrm{C}$ for $10 \mathrm{~min}$ leads to nanocomposite structures with excellent magnetic properties. The coercivity decreased with increasing Fe cluster content, while the energy product initially increased, reaching a maximum of almost 18 MGOe, and then decreased at higher Fe cluster content. Secondary heat treatment at $500{ }^{\circ} \mathrm{C}$ significantly improved the magnetic properties when compared with the single-step heat treatment at $600^{\circ} \mathrm{C}$. Increased coercivity and remanence was observed, resulting in energy products of 21 MGOe. The energy products are close to 70 percent greater than expected for uncoupled systems.
\end{abstract}

Keywords: Cluster; Exchange-coupling; Energy product

\section{Introduction}

Cluster-assembled magnetic materials have received significant attention because of the many potential applications $[1,2]$. Particularly, cluster assembly offers the opportunity to produce tailored nanostructures with excellent control of scale and phase fraction. Cluster assembly is thus well-suited for the production of nanocomposite exchangespring permanent magnets.

Nanocomposite exchange-spring permanent magnets have generated a significant amount of attention in the last dozen years. The combination of soft and hard magnetic phases, assembled at the nanoscale, results in high remanence and concomitant high-energy products when compared to conventional, non-exchange-coupled permanent magnet materials. For example, isotropic, non-interacting $\mathrm{Nd}-\mathrm{Fe}-\mathrm{B}-$ based magnets have energy products of 12-14 MGOe and a theoretical maximum of 16 MGOe [3], while nanocomposite permanent magnets based in the same system have achieved energy products greater than 20 MGOe
[4]. However, the magnetic properties critically depend on a uniform, nanoscale soft magnetic phase that enables it to be completely exchange-coupled to the hard magnetic phase. Non-ideal structures with larger soft-magnetic grains provide magnetic reversal initiation sites in the uncoupled regions [5], resulting in inferior magnetic properties.

Practically, obtaining ideal nanostructures is difficult. Conventional melt processing or devitrification routes generally lack the necessary uniformity and scale $[6,7]$. Cluster assembly routes offer the advantage of uniform size distributions and sub-ten nanometer size ranges. Colloidal methods have been widely used to make nanoscale particles of many different materials $[8,9]$, and recently to produce exchange-spring permanent magnets in the $\mathrm{Fe}_{3} \mathrm{Pt} / \mathrm{FePt}$ system [10]. Here, energy products of isotropic magnets reached approximately $20 \mathrm{MGOe}$. Likewise, cluster formation via gas aggregation $[11,12,13]$ has been used extensively to product nanoscale magnetic particles $[14,15,16$, $17,18,19,20,21]$. Rui et al. [22] reported, in a preliminary study, on cluster-assembled exchange-spring perma- 
nent magnets assembled using gas aggregation cluster formation. Here, we extend that study and report cluster-assembled exchange-spring permanent magnets with energy products above 20 MGOe.

\section{Experimental procedures}

Clusters were fabricated by the gas-aggregation technique [23] in which Fe clusters are formed through collisions with the Ar ions. The atomic gas was produced by DC magnetron sputtering from a 99.95 percent pure $\mathrm{Fe}$ target. The base pressure of the system was below $10^{-7}$ Torr, and an $\mathrm{Ar} / \mathrm{He}$ gas mixture was introduced into the nucleation chamber. He gas was used to ensure uniform temperature in the nucleation chamber. The He gas flow rate was varied from 250 to $300 \mathrm{sccm}$ while the Ar gas flow rate was varied between 250 and $350 \mathrm{sccm}$. The sputtering power also influences cluster size and size distribution. In this study, it was varied between 60 and $160 \mathrm{~W}$, although most depositions were done at a power level of $160 \mathrm{~W}$.

The gas aggregation system is also equipped with a second DC magnetron sputtering source, and an AC magnetron sputtering source, both currently situated perpendicular to the cluster source. The AC source was used to deposit a $\mathrm{C}$ overlay to protect the deposited material from oxidation. The DC source was used to deposit hard magnetic FePt thin films, and alternating deposition between the cluster gun and the second DC magnetron gun allowed the development of nanocomposite structures, with the clusters imbedded in the FePt phase. The nanocomposite structures were fabricated by alternating deposition of FePt and Fe clusters by physically rotating the substrate for deposition from the cluster or thin film source. The relative fraction of Fe clusters and FePt film was controlled by varying deposition times from each source. The relative volume fraction of each phase was determined from the respective sputtering rates and the deposition times, and the accuracies were on the order of 10 percent. The material was deposited directly on a carbon support grid for transmission electron microscopy and, simultaneously, a Si substrate for characterization by X-ray diffraction and magnetometry. Heat treatments were accomplished in a controlled atmosphere rapid thermal annealing system.

The clusters and nanocomposite structures were characterized by transmission electron microscopy using a JEOL2010 transmission electron microscope operating at $200 \mathrm{kV}$. Energy-filtered TEM images were acquired using the three-window technique using a Tecnai F20ST equipped with a Gatan imaging filter. Energy loss images were taken at the $\mathrm{Fe}$ and Pt edges. X-ray diffraction data were collected using a Rigaku D/Max-B diffractometer with $\theta-\theta$ geometry and a Bruker AXS D8 Discover diffractometer with an area detector in the $\theta-\theta$ geometry. Magnetic measurements were conducted at room temperature using a Quan- tum Design MPMS SQUID magnetometer and an alternating gradient field magnetometer. Magnetic Force Microscopy (MFM) images were obtained from a Digital Instrument Nanoscope IIIa Dimension 3100 Scanning Probe Microscopy with a high coercivity and low stray field MFM tip. The magnetic signal from the substrate was subtracted from the nanocomposite magnetic signal by fitting a straight line to the high-field region and subtracting the linear portion from the measured signal.

\section{Results and discussions}

The size and the size distribution of Fe clusters can be controlled by adjusting the various processing parameters, including gas pressure and sputtering power. By carefully selecting the processing parameters, nearly monodispersed Fe clusters can be produced, with sizes tailored between 4 and $20 \mathrm{~nm}$ and $\sigma / d$ ratios on the order of 0.1 ( $\sigma$ is the standard deviation, while $d$ is the average size of the clusters). Electron diffraction patterns revealed that the clusters are BCC $\alpha$-Fe (Fig. 1).

Nanocomposite structures consisting of $8 \mathrm{~nm}$ Fe clusters imbedded in an FePt matrix were fabricated by alternate deposition from two sources. The as-deposited $\mathrm{FePt}$ film was in the disordered A1 FCC structure. Therefore, heat treatments were necessary to form the hard magnetic $\mathrm{L} 1{ }_{0}$ structure. Heat treatment at $600{ }^{\circ} \mathrm{C}$ for $10 \mathrm{~min}$ resulted

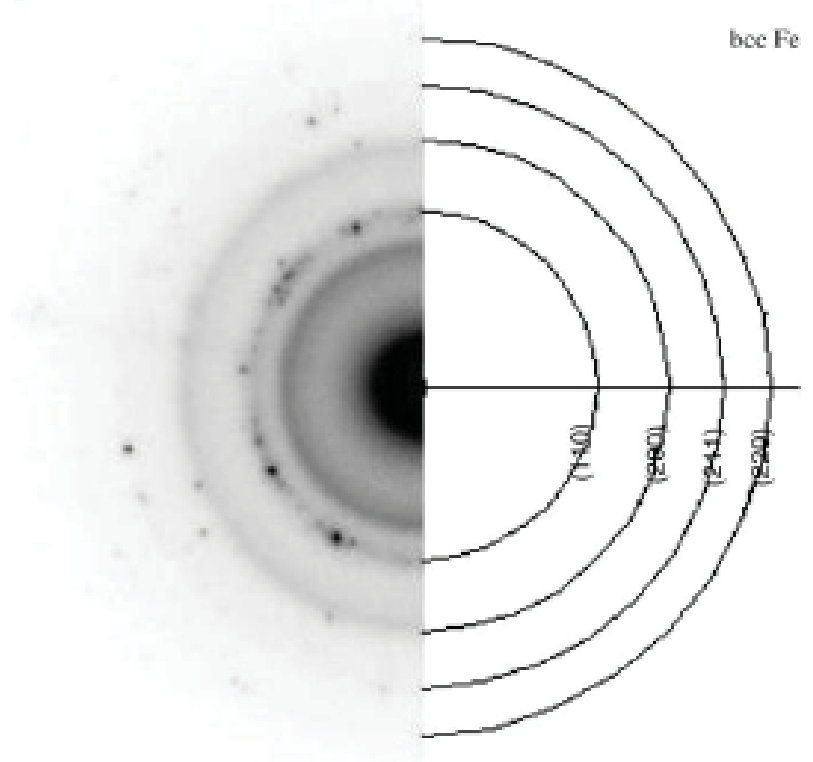

Fig. 1. Electron diffraction pattern revealed a single-phase BCC $\alpha$-Fe structure. 
in the highest coercivity values (above $10 \mathrm{kOe}$ ). FePt thin films deposited on Si displayed random crystallographic orientation after heat treatment (Fig. 2) [24].

Different phase contents in the nanocomposite structures were achieved by varying the deposition times for the Fe clusters while keeping the total FePt thickness constant. Nanocomposite structures containing between 0 and $30 \mathrm{vol} \% \mathrm{Fe}$ clusters were fabricated, and these structures were heat treated at $600{ }^{\circ} \mathrm{C}$ for $10 \mathrm{~min}$. The coercivity of the nanocomposite structures decreased with increasing Fe cluster content. The FePt L1 ${ }_{0}$ film, with no Fe clusters, exhibited a coercivity of greater than $10 \mathrm{kOe}$, which decreased to $0.5 \mathrm{kOe}$ at $30 \mathrm{vol} \%$ of the Fe clusters. The remanence increased systematically with $\mathrm{Fe}$ cluster content, while the energy product went through a maximum of 17.7 MGOe. Fig. 3 shows demagnetization curves for the various samples, while Fig. 4 summarizes the magnetic

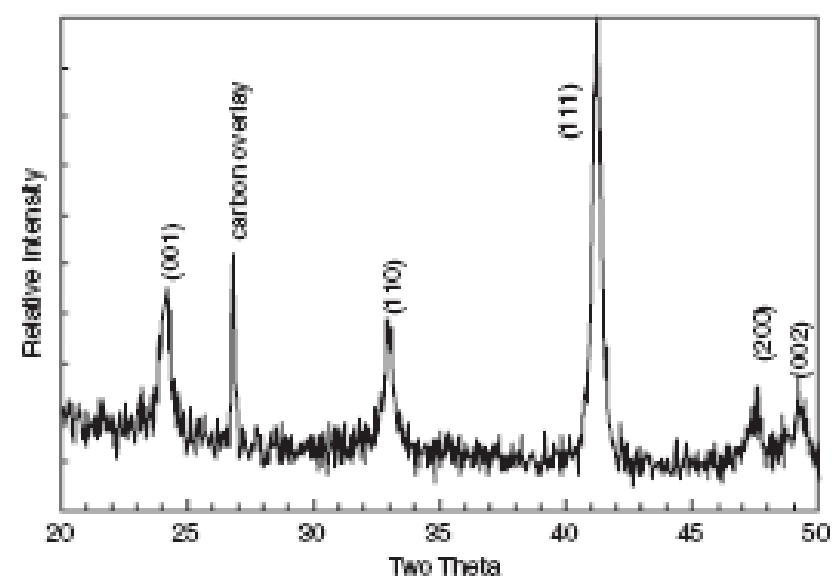

Fig. 2. X-ray diffraction pattern of $\mathrm{FePt}$ heat-treated at $600{ }^{\circ} \mathrm{C}$ for $10 \mathrm{~min}$ showing the formation of the single-phase $\mathrm{L}_{0}$ structure.

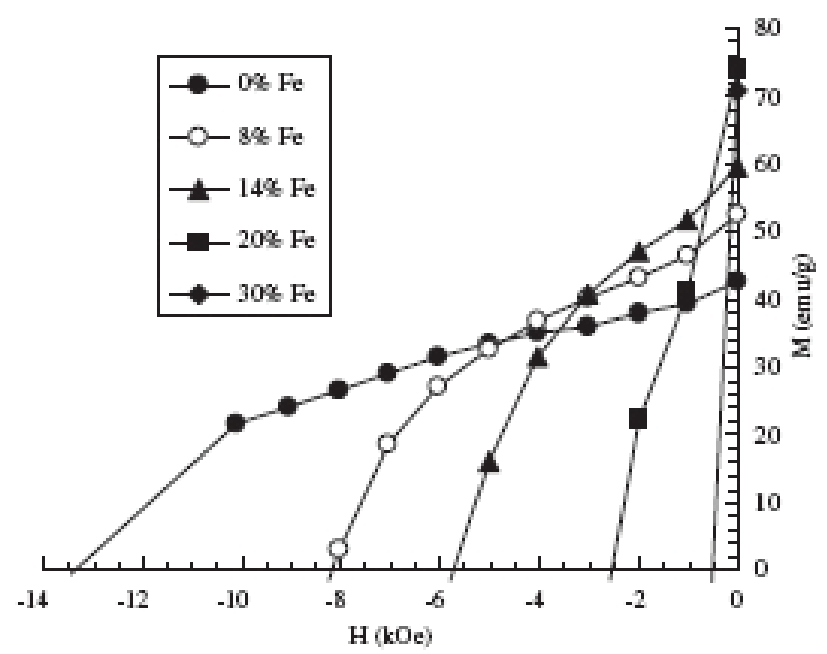

Fig. 3. Hysteresis curves for the nanocomposite films with different $\mathrm{Fe}$ cluster content (at $300 \mathrm{~K}$ ). The solid circles are the FePt film, and the coercivity decreases with increasing fraction of Fe clusters.

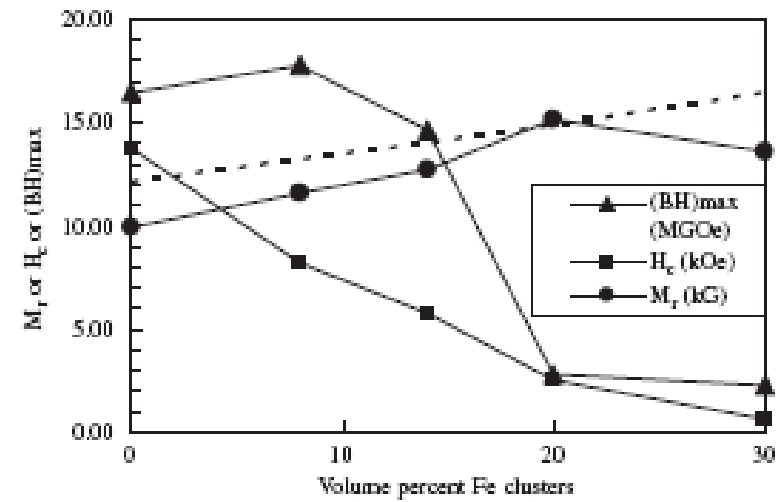

Fig. 4. Summary of magnetic properties of nanocomposite films $\left(=H_{\mathrm{c}}\right.$ $(\mathrm{kOe}), \bullet=M_{\mathrm{r}}(\mathrm{kG}), \boldsymbol{\Delta}=(B H)_{\max }(\mathrm{MGOe})$, the dashed line is the theoretical maximum energy product for a non-interacting, isotropic system).

properties. The dashed line in Fig. 4 is the theoretical maximum energy product for a non-interacting, isotropic system calculated from the equation $(B H)_{\max }=\left(4 \pi M_{\mathrm{r}}\right)^{2} /$ $4=\left(4 \pi M_{\mathrm{s}}\right)^{2} / 16$ where $4 \pi M_{\mathrm{r}}=1 / 2\left(4 \pi M_{\mathrm{s}}\right), M_{\mathrm{r}}$ is the remanent magnetization, and $M_{\mathrm{s}}$ is the saturation magnetization. $4 \pi M_{\mathrm{s}}$ was calculated using a rule of mixtures approach using saturation values of $14.1 \mathrm{kG}$ for the $\mathrm{L} 1_{0}$ FePt structure [25] and $21.6 \mathrm{kG}$ for $\alpha$-Fe. The energy products were well above the calculated values, suggesting that exchange interactions improve the remanence above the StonerWohlfarth limits. The energy product increased upon addition of $\mathrm{Fe}$ clusters, and the values were well above those expected for randomly oriented, non-interacting magnetic systems. Small steps can be observed for all the hysteresis loops in the second quadrant; this is likely because the FePt is not fully ordered after annealing.

The effect of secondary annealing on the magnetic properties was also investigated. Samples with 8 and 14 vol\% Fe clusters were heat treated at $500{ }^{\circ} \mathrm{C}$ for 10 and $20 \mathrm{~min}$ after the $600{ }^{\circ} \mathrm{C} / 10 \mathrm{~min}$ heat treatments. The step in the second quadrant that was present after the $600{ }^{\circ} \mathrm{C}$ heat treatment was essentially eliminated, and a marked increase in coercivity and remanence was observed for both samples (Fig. 5). A concomitant improvement in energy product was produced, reaching nearly 21 MGOe $\left(168 \mathrm{~kJ} / \mathrm{m}^{3}\right)$ for both samples (Fig. 6). This value is similar to the highest values reported for isotropic nanocomposite permanent magnets $[2,10]$. The second heat treatment at $500{ }^{\circ} \mathrm{C}$ likely improves the magnetic properties by improving the ordering of the $\mathrm{L}_{0}$ structure. The improvement in properties after the secondary heat treatment may also be associated with a modification of the $\mathrm{Fe} / \mathrm{FePt}$ interface structure. The variable composition across the $\mathrm{Fe} / \mathrm{FePt}$ interface results in a gradient in the anisotropy constant, which more effectively resists demagnetization, similar to what has been observed in multilayer systems [26, 27].

MFM revealed a correlation between the domain structure and $\mathrm{Fe}$ cluster content for the heat-treated samples 

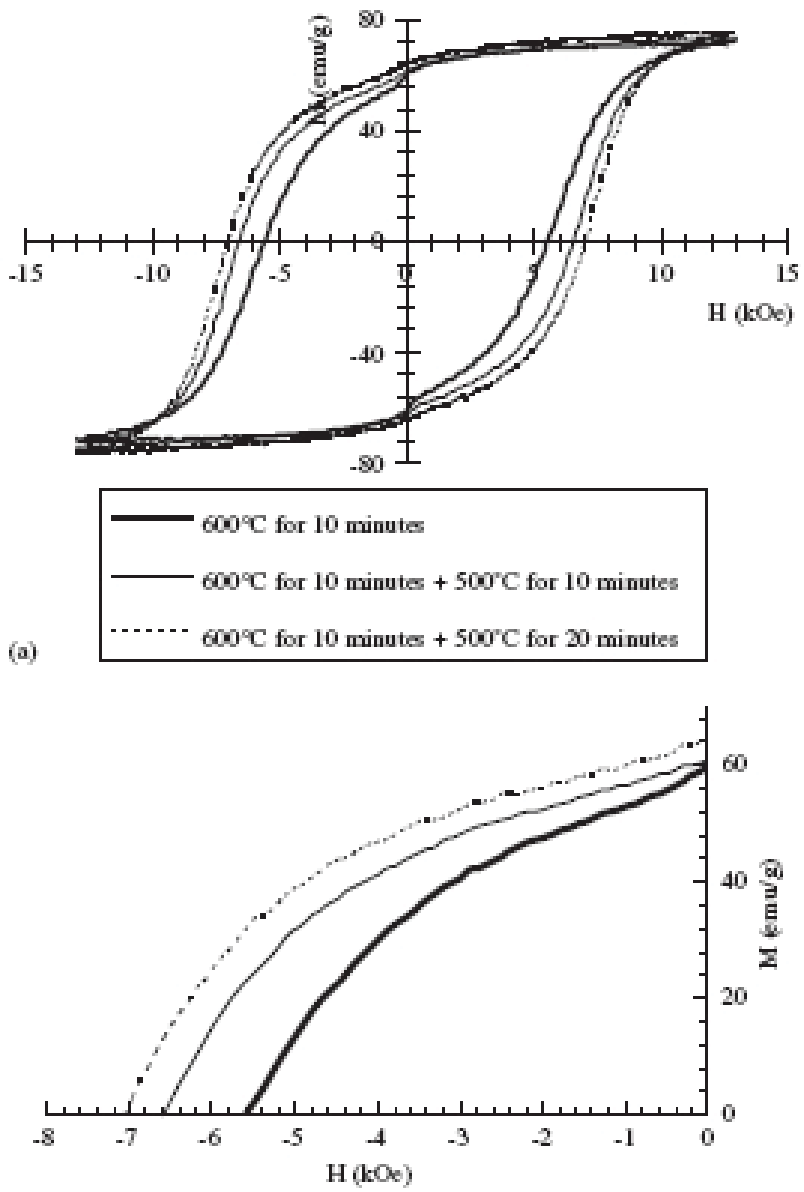

(b)

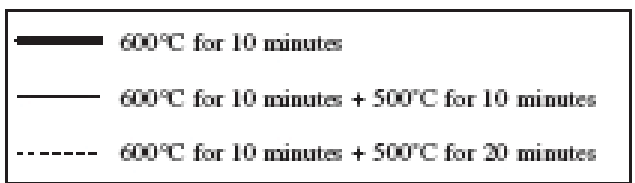

Fig. 5. (a) Hysteresis loops and (b) demagnetization curves of the $14 \mathrm{vol} \%$ $\mathrm{Fe}$ clusters/FePt nanocomposite heat treated at various conditions.

(Fig. 7). The scale of the magnetic domains in all samples was well above the grain size, indicating that the domains observed by MFM are "interaction domains." Notably, the scale of the domains decreased with increasing Fe cluster content. Generally, the scale of interaction domains has been shown to scale with $(\mathrm{AK})^{1 / 2}$, similarly to the single domain limit relationship. Thus, a decreasing interaction domain size may indicate a decreasing anisotropy with increasing Fe cluster content, which likely arises from the strong exchange interactions and low anisotropy of Fe. The decreased anisotropy in these exchange-spring nanocomposites is similar to the decrease in anisotropy observed in soft magnetic materials as exchange interactions increase (i.e., random anisotropy model).

The dissolution of Fe clusters during heat treatment is possible, given the solubility of the FePt phase. Therefore,
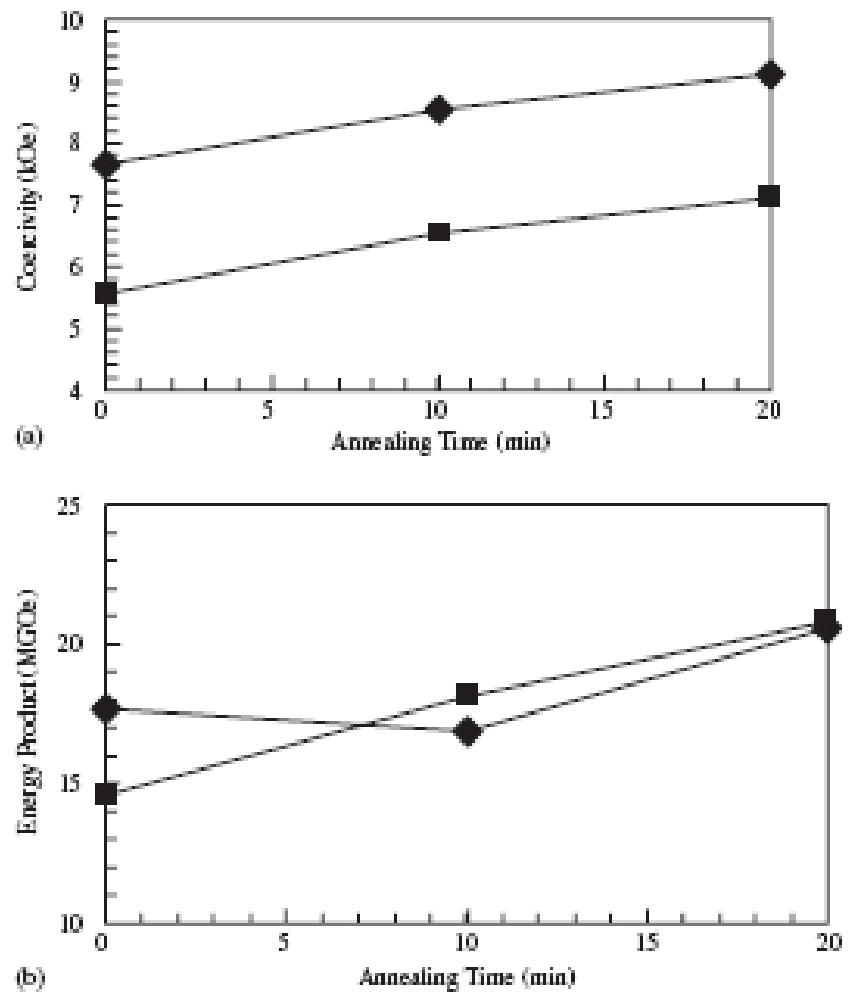

Fig. 6. Relation between (a) coercivity and (b) energy product for samples with $8(\diamond)$ and $14(-)$ vol\% Fe clusters annealed at $500{ }^{\circ} \mathrm{C}$ for 10 and $20 \mathrm{~min}$ after annealing at $600{ }^{\circ} \mathrm{C}$ for $10 \mathrm{~min}$.

efforts to characterize the as-deposited and heat-treated nanocomposite structures have been made utilizing several techniques. However, structural characterization of these materials, particularly the observation of the Fe clusters, provides significant challenges. For instance, the scale of the Fe clusters $(\sim 8 \mathrm{~nm})$ would produce $\mathrm{X}$-ray diffraction peak broadening on the order of $1^{\circ}$ full-width at half-maximum, calculated from the Scherrer equation. This, along with the relatively low volume fraction of the Fe clusters, limits detectability by diffraction techniques. Fig. 8 shows an X-ray diffraction pattern of as-deposited $\mathrm{Fe} / \mathrm{FePt}$ nanocomposite with $30 \mathrm{vol} \% \mathrm{Fe}$ clusters, along with a Rietveld refinement of the A1 FePt phase. Even with the Rietveld refinement, the (1 110$) \alpha$-Fe peak is difficult to discern (its position is marked on the figure with an arrow). Heat treatment further obscures this peak, as the A1 $\left\{\begin{array}{lll}2 & 0 & 0\end{array}\right\}$ peak splits due to the tetragonality of the $\mathrm{L} 1_{0}$ structure, and further refinement of the Fe clusters due to partial dissolution results in even more extensive peak broadening (see below). Transmission electron microscopy investigation successfully revealed the structure of $\mathrm{Fe} / \mathrm{FePt}$ nanocomposites prior to heat treatment (Fig. 9(a)).However, formation of the $\mathrm{L} 1_{0}$ structure results in a more complicated structure due to twinning and formation of larger $\mathrm{L}_{0}$ grains, resulting in a greater degree of diffraction contrast which significantly hinders clear distinction of the Fe clusters (Fig. 9(b)).Energy-filtered TEM was also unable to clearly dis- 

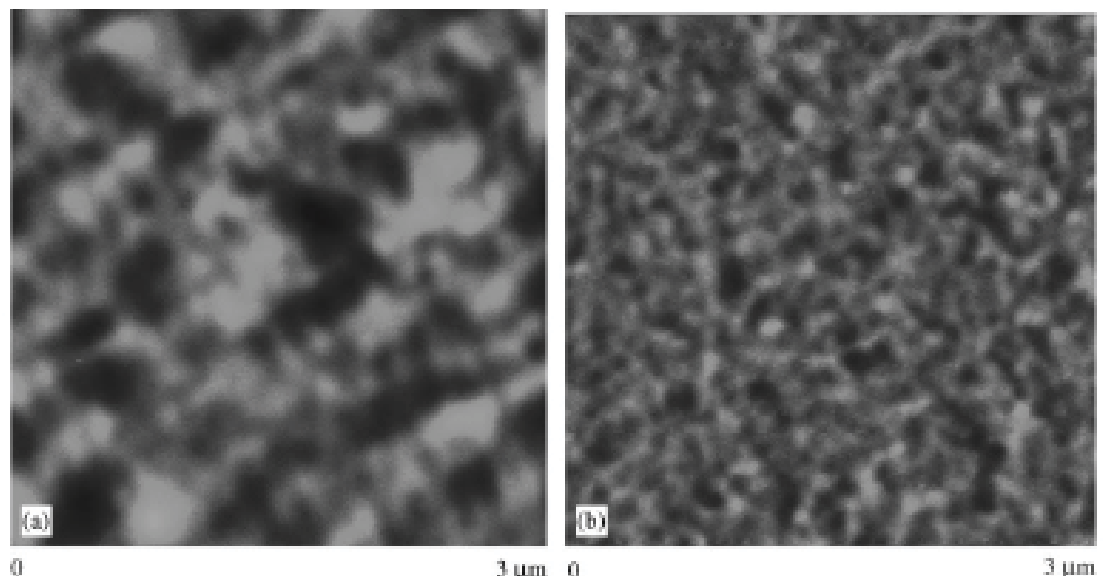

Fig. 7. MFM images of (a) single phase FePt annealed at $600{ }^{\circ} \mathrm{C}$ for $10 \mathrm{~min}$ and (b) nanocomposite with 8 vol\% Fe clusters in FePt annealed at $500{ }^{\circ} \mathrm{C}$ for $20 \mathrm{~min}$ after having been annealed at $600{ }^{\circ} \mathrm{C}$ for $10 \mathrm{~min}$.

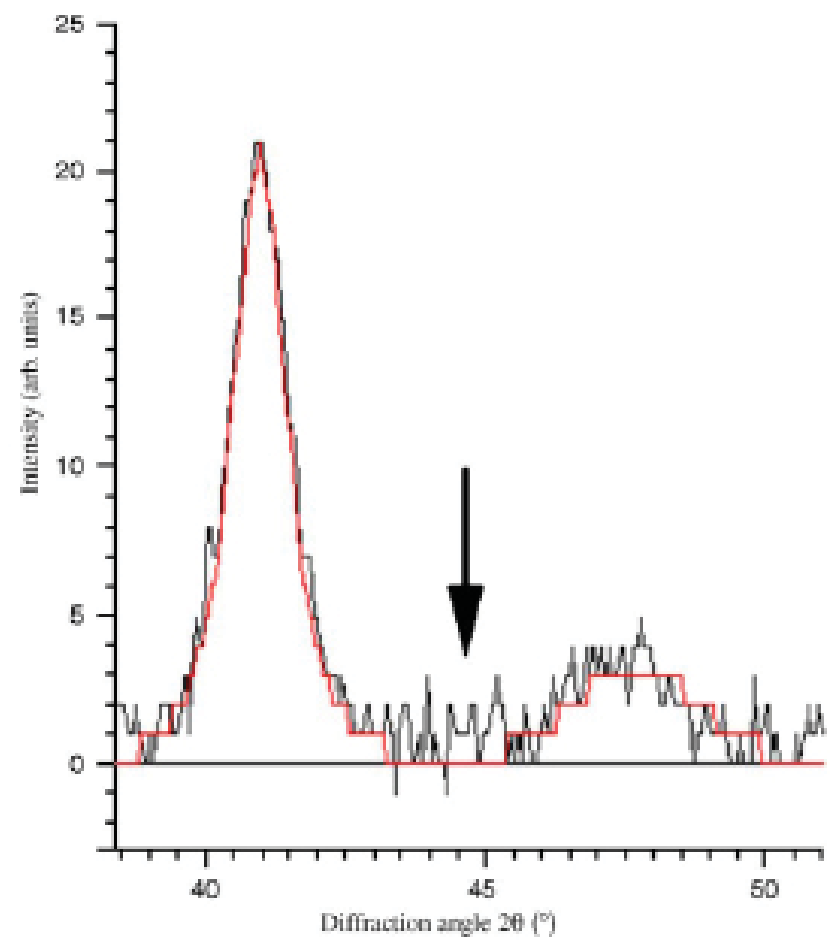

Fig. 8. X-ray diffraction pattern of $\mathrm{FePt} / \mathrm{Fe}$ cluster nanocomposite prior to heat treatment, along with the Rietveld analysis for the A1 FePt structure. The $\left(\begin{array}{lll}1 & 1 & 0\end{array}\right) \alpha$-Fe peak is at approximately $44.6^{\circ}$.

inguish Fe clusters, likely due to the compositionally graded $\mathrm{Fe} / \mathrm{FePt}$ interfaces and the resolution limit of that technique, although it is also possible that the clusters dissolved into the FePt matrix during heat treatment.

Since it is difficult to confirm the existence of Fe clusters in the heat-treated samples utilizing a number of characterization techniques, the diffusion profiles have been calculated in order to understand the potential dissolution possibilities. The diffusion profiles were calculated by solving Fick's second law for the case of a diffusion cou- ple, assuming that the nanocomposite is a $\mathrm{Fe} / \mathrm{FePt}$ diffusion couple, resulting in the equation

$$
\mathrm{C}=\frac{\mathrm{C}_{1}+\mathrm{C}_{2}}{2}-\frac{\mathrm{C}_{1}-\mathrm{C}_{2}}{2} \operatorname{erf}\left[\frac{\mathrm{x}}{2} \operatorname{erf} \sqrt{\mathrm{Dt}}\right]
$$

where $C$ is the concentration of $\mathrm{Fe}$ or $\mathrm{Pt}$ as a function of position $x$ and time $t, C_{1}$ and $C_{2}$ are the concentrations of $\mathrm{Fe}$ or Pt in each side of the diffusion couple, and $D$ is the diffusivity. Diffusion data for the diffusion of $\mathrm{Fe}$ in $\mathrm{FePt}$ [28] and Pt in $\gamma$-Fe [29] were utilized (Table 1). No data for $\mathrm{Pt}$ diffusion in $\alpha$-Fe was available, to our knowledge. Note that using $\gamma$-Fe would provide an overestimation of the diffusion of Pt in $\mathrm{Fe}$, given that $\gamma$-Fe and Pt are both FCC and thus would have higher interdiffusion rates $\left(600^{\circ} \mathrm{C}\right.$ is well below the $\alpha$-to- $\gamma$ transformation temperature of $912{ }^{\circ} \mathrm{C}$ ). Fig. 10 clearly shows that the Fe clusters are not dissolved into the FePt structure for the heat treatments used in this study. The secondary annealing (at $500{ }^{\circ} \mathrm{C}$ ) produces an inconsequential change in the diffusion profile (diffusion lengths are on the order of $0.5 \mathrm{~nm}$ ). The diffusion analysis strongly supports the existence of Fe clusters after heat treatment. Further efforts at structural characterization using high-energy X-ray sources are underway.

\section{Conclusions}

The size and the size distribution of $\alpha$-Fe clusters can be controlled by adjusting processing parameters during gas aggregation. Monodispersed clusters below $10 \mathrm{~nm}$ were readily obtained. Fe cluster/FePt nanocomposites were fabricated by alternate deposition from two different sources, and the volume fraction of $\mathrm{Fe}$ varied between 0 and 0.3 . The magnetic properties strongly depend on the phase content of the $\mathrm{FePt} / \mathrm{Fe}$ clusters nanocomposites. Energy products on the order of 18 MGOe were realized in the twophase system, and were increased over single-phase mate- 

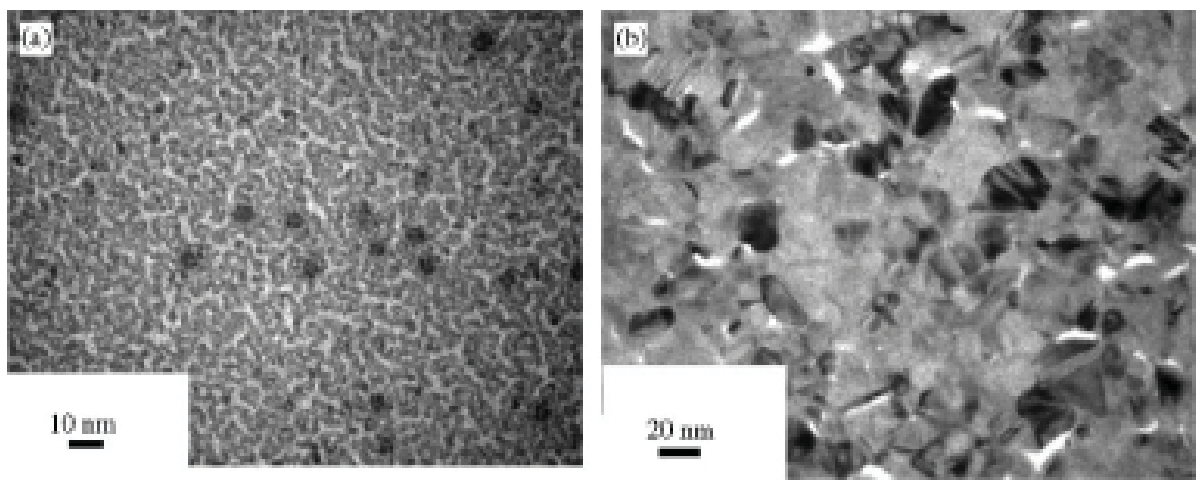

Fig. 9. (a) TEM micrograph showing the nanocomposite FePt/Fe cluster system prior to heat treatment. (b) TEM micrograph of the Fe/FePt nanocomposite after heat treatment at $600^{\circ} \mathrm{C}$ for $10 \mathrm{~min}$. Picture (a) was FePt/Fe cluster bilayer structure and Picture (b) was FePt/Fe clusters/FePt "sandwich" structure.

Table 1

Diffusion data used to cakulate the diffusion profiles $\left(D=D_{0} e^{-0 / R r}\right)$ (from [28,29])

\begin{tabular}{lll}
\hline Diffusing spedes & $Q(\mathrm{~kJ} / \mathrm{mal})$ & $D_{0}\left(\mathrm{~cm}^{2} / \mathrm{s}\right)$ \\
\hline Fe in FePt & 292.2 & 1.0 \\
$\mathrm{Pt}$ in $\mathrm{\gamma}-\mathrm{Fe}$ & 283 & 2.1 \\
\hline
\end{tabular}
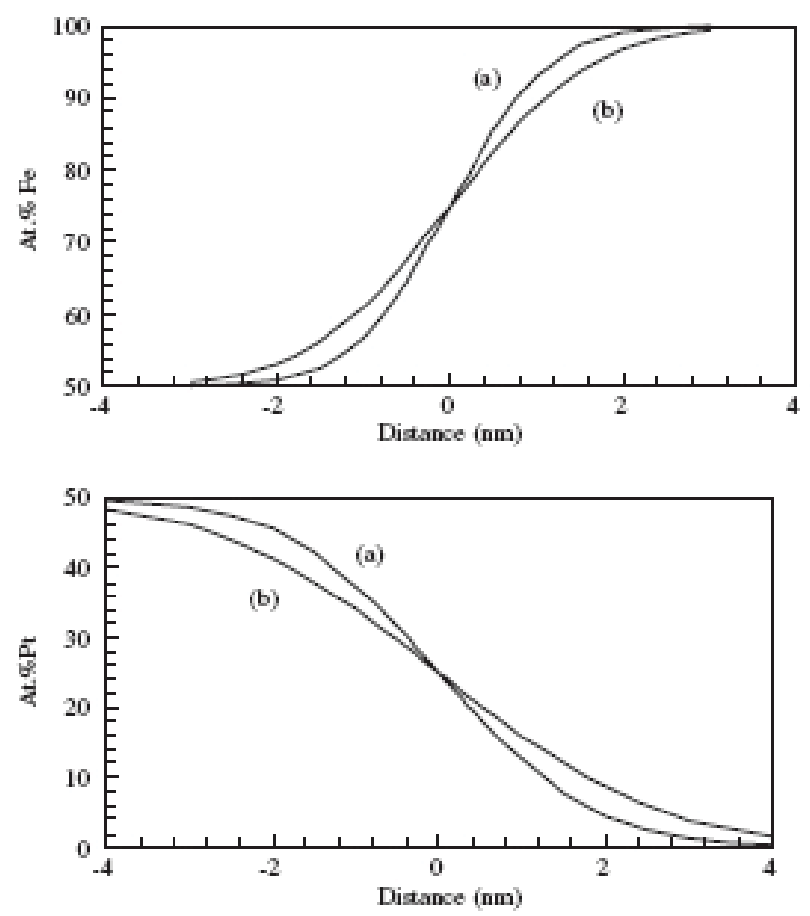

Fig. 10. Diffusion profiles calculated for Fe diffusion in FePt (top) and Pt diffusion in $\mathrm{Fe}$ (bottom) for (a) $10 \mathrm{~min}$ and (b) $20 \mathrm{~min}$ at $600^{\circ} \mathrm{C}$. The distance at 0 is considered the interface between FePt (left side of graphs) and Fe clusters (right side of graphs).

rials. The coercive force decreased with increasing Fe cluster content, but was reasonably high $(5.7 \mathrm{kOe})$ at $14 \mathrm{vol} \%$ $\mathrm{Fe}$ clusters. A secondary heat treatment at $500{ }^{\circ} \mathrm{C}$ further improved the coercivity values and energy products (to
21 MGOe). The increase in properties was attributed to a refinement in the (long-range) $\mathrm{L} 1_{0}$ ordering and a modification of the interface structure between the Fe clusters and FePt matrix. A diffusion analysis revealed the likelihood that $\mathrm{Fe}$ clusters were not dissolved into the FePt matrix.

\section{Acknowledgments}

The authors appreciate assistance from B. Jones for the Xray diffraction analysis, $\mathrm{X}$. Li for assistance with analyzing the electron diffraction patterns, and J. Kostogorova for assistance with the Rietveld analysis. This work was supported by the National Science Foundation through MRSEC: QSPINS (Grant no. 0213808), and support from the Army Research Office, Department of Energy, and the Center for Materials Research and Analysis is greatly appreciated.

\section{References}

1. S.N. Piramanayagam, Y. Xu, D.Y. Dai, L. Huang, S.I. Pang and J.P. Wang, J. Appl. Phys. 91 (2002), p. 7685.

2. S. Stoyanov, V. Skumryev, Y. Zhang, Y. Huang and G. Hadjipanayis, J. Appl. Phys. 93 (2003), p. 7592.

3. B.M. Ma, J.W. Herchenroeder, B. Smith, M. Suda, D.N. Brown and Z. Chen, J. Magn. Magn. Mater. 219 (2002), p. 418.

4. J. Bernardi, T. Schrefl, J. Fidler, Th. Rijks, K. deDort, V. Archambault, D. Pere, S. David, D. Givord, J.F. O'Sullivan, P.A.I. Smith, J.M.D. Coey, U. Czernik and M. Gronefeld, J. Magn. Magn. Mater. 219 (2000), p. 186.

5. Y. Gao, D. Shindo and A.K. Petford-Long, J. Appl. Phys. 93 (2003), p. 8119.

6. J.E. Shield, Y. Liu, R. Marr, Z. Chen and B.M. Ma, IEEE Trans. Magn. 40 (2004), p. 2901.

7. J.E. Shield, Y. Liu and R. Marr, J. Magn. Magn. Mater. 284 (2004), p. L1. 
8. A. Schmitt, A. Fernández-Barbero, M.A. Cabrerizo-Vílchez and R. Hidalgo-Álvarez, J. Phys.: Condens. Matter 12 (2000), p. 281.

9. L. Manna, E.C. Scher and A.P. Alivisatos, J. Clust. Sci. 13 (2002), p. 521.

10. H. Zeng, J. Li, J.P. Liu, Z.L. Wang and S. Sun, Nature (London) 420 (2002), p. 395.

11. H. Haberland, M. Karrais, M. Hall and Y. Thurner, $J$. Vac. Sci. Technol. A 10 (1992), p. 3266.

12. S.H. Baker, S.C. Thornton, A.M. Keen, T.I. Preston, C. Norris, K.W. Edmonds and C. Binns, Rev. Sci. Instrum. 68 (1997), p. 1853.

13. S.H. Baker, S.C. Thornton, K.W. Edmonds, M.J. Maher, C. Norris and C. Binns, Rev. Sci. Instrum. 71 (2000), p. 3178.

14. C. Binns, M.J. Maher, Q.A. Pankhurst, D. Kechrakos and K.N. Trohidou, Phys. Rev. B 66 (2002), p. 184413.

15. M.D. Upward, B.N. Cotier, P. Moriarty, P.H. Beton, S.H. Baker, C. Binns and K. Edmonds, J. Vac. Sci. Technol. B 18 (2000), p. 2646.

16. K.W. Edmonds, C. Binns, S.H. Baker, S.C. Thornton, C. Norris, J.B. Goedkoop, M. Finazzi and N.B. Brookes, Phys. Rev. B 60 (1999), p. 472.

17. D.L. Peng, T. Hihara, K. Sumiyama and H. Morikawa, J. Appl. Phys. 92 (2002), p. 3075.

18. T. Vystavel, G. Palasaritzas, S.A. Koch and J.Th.M. DeHosson, Appl. Phys. Lett. 82 (2002), p. 197.
19. Y. Xu, Z.G. Sun, Y. Qiang and D.J. Sellmyer, J. Appl. Phys. 93 (2003), p. 8289.

20. S. Stappert, B. Rellinghaus, M. Acet and E.F. Wassermann, J. Crystal Growth 252 (2003), p. 440.

21. D.J. Sellmyer, M.L. Yan, Y.F. Xu and R. Skomski, IEEE Trans. Magn. 41 (2005), p. 560.

22. X. Rui, Z.G. Sun, Y. Xu, D.J. Sellmyer and J.E. Shield, J. Appl. Phys. 97 (2005), p. 10K310.

23. D.J. Sellmyer, C.P. Luo, Y. Qiang and J.P. Liu In: H.S. Nalwa, Editor, Handbook of Thin Films, Nanomaterials and Magnetic Thin Films vol. 5, Academic Press, New York (2002), p. 337.

24. P. Rasmussen, X. Rui and J.E. Shield, Appl. Phys. Lett. 86 (2005), p. 191915.

25. R. Skomski, J. Phys.: Condens. Matter 15 (2003), p. R841.

26. D.C. Crew, L.H. Lewis, J. Kim and K. Barmak, J. Appl. Phys. 89 (2001), p. 7528.

27. J.S. Jiang, J.E. Pearson, Z.Y. Liu, B. Kabius, S. Trasobares, D.J. Miller, S.D. Bader, D.R. Lee, D. Haskel, G. Srajer and J.P. Liu, J. Appl. Phys 97 (2005), p. 10K311.

28. In: E.A. Brandes, Editor, Smithells Metals Reference Book, Butterworths, Boston (1983).

29. B. Million and J. Kucera, Kovove Mater. 11 (1973), p. 300. 